\title{
El temor de Atenas: una aproximación levinasiana al teatro ático y la negación del Otro por la máscara
}

\section{The Fear of Athens: A Levinasian Approach to Attic Theatre and the Negation of the Other by the Mask}

\author{
Víctor lbarra \\ Universidad Diego Portales, Chile \\ v.ibarra.b@gmail.com
}

\section{Resumen:}

Este artículo pretende establecer una lectura del fenómeno de la máscara en el teatro ático del siglo $\mathrm{V}$ a. C. a la luz del problema de la negación del Otro por la ontología, desarrollado por Emmanuel Lévinas. El ocultamiento a través de la imposición de la máscara en la faz del actor tendría, en el contexto de Atenas, otros correlatos, negaciones compulsivas de la división al interior de la ciudad. Este afán del discurso ateniense por exaltarse como un Mismo indiviso pone en práctica una serie de estrategias para erradicar el peligro que encarna la alteridad para la continuación de esa autorrepresentación sólida. Rostro y máscara reproducen una pugna que es posible rastrear, mediante la revisión de las fuentes trágicas: corroboramos, entonces, que el problema de la expresión, presente en la categoría de rostro

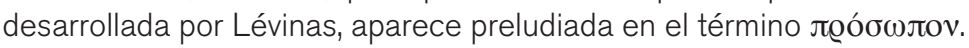

Palabras clave: máscara, teatro ático, otro, rostro, Lévinas.

\begin{abstract}
:
This paper pretends to establish a reading of the phaenomenon of the mask in Attic theatre (5th century b. C.) regarding the problem of the negation of the Other by ontology proposed by Lévinas. The concealment through the imposition of the mask in front of the face of the actor would have, in the context of Athens, other correlations, compulsive negations of the discord inside of the city. This eagerness of the Athenian discourse to hail itself as an undivided Self practices a set of strategies to erradicate the danger, implied in the otherness, to the continuity of this solid self-representation. Therefore, the countenance and the mask reproduce a conflict that we can trace through the revision of tragic sources: we corroborate that the problem of the expression, present in the category of countenance

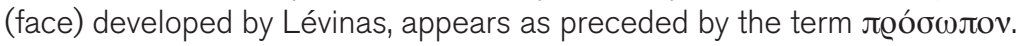

Keywords: Mask, Attic theatre, Other, Countenance, Lévinas. 


\section{I}

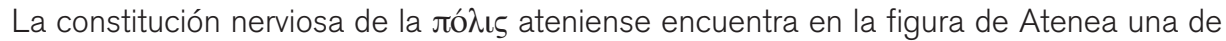
sus fuentes primordiales. Entre la ciudad y el numen, el intercambio ha sido vasto: desde la predilección por el olivo frente al pequeño mar de Poseidón -y el posterior sacrificio del sufragio femenino para calmar la cólera del dios submarino- ${ }^{1}$, hasta la resolución del juicio de Orestes gracias al doble voto de la divinidad y la amenaza que convierte a las Erinias en simples Euménides, los temores de Atenea han sido, sin lugar a dudas, los temores atenienses.

El castigo de la Medusa encarna la principal alergia de la hija de Zeus y signa, pese a su origen argólico y no ático, el destino de Atenas. "[...] [D]icen [...] que la Gorgona quiso competir en belleza con aquélla” (Apolodoro II.4.2) y que, en venganza, la muchacha es convertida en un monstruo mortal, desgraciada, condenada a vivir al otro lado del Océano con sus hermanas; única de entre las cuales transforma a los hombres en piedra con la mirada. Se vuelve insoportable a la vista; su rostro es víctima de la prescripción olímpica que encontrará en Perseo la materialidad para destruir la amenaza del Otro, fundamentando para siempre la mediación de la alteridad a través de su reflejo en un escudo. Ese escudo será la máscara que permita al hijo de Dánae no mirar en derechura a la Medusa y decapitar su cabeza, así como también evitar la enseñanza de ese rostro (que, dada la sobrenaturalidad de la gorgona, viene desde la altura, como la palabra del maestro).

Atenea, habiendo nacido de la cabeza de su padre como exaltación del Mismo, inventa al Otro para destruirlo a través de la subsunción de su rostro al reflejo en el escudo y, entonces, permite a Perseo comprender la expresión de la gorgona, que ha perdido su condición de mandato en la escuálida representación que la tematiza. El rostro de Medusa queda fijado, enmascarado en la ontología del escudo que la hace aprehensible a los ojos del héroe, quien "[...] guiando Atenea su mano se volvió y miró al escudo de bronce por medio del cual veía la imagen de la Gorgona, y le cortó la cabeza" (Apolodoro II.4.2).

Esta interpretación del mito de la Medusa, que establece una analogía entre el escudo y la máscara, deja entrever una definición del Otro más cercana a la expresión del rostro en Lévinas que a la simple negación del yo platónico-hegeliana. La gorgona no aparece únicamente como la irracionalidad en contra de la civilización de Atenea -diosa de la sabiduría-, vale decir, no se reduce al enfrentamiento del no-yo y del yo. Supone temor en la hija de Zeus frente a la posibilidad que oculta la expresión del monstruo que ella misma ha permitido en el horizonte griego como alergia primera: la respuesta otorgada, de manera efectiva, al mandato de ese rostro. En primer término, frente al desafío de la belleza, Atenea castiga (vale decir, no ignora, responde a la apelación de la mortal). Luego, consciente de esta concesión, se ve obligada a negar la autonomía de ese Otro - que la ha sustraído del gozo de su morada divina-, permitiendo a los hombres comprenderlo y, por

1 Cfr. Detienne, Marcel. “Una autoctonía de inmaculada concepción: nuestros atenienses”. Cómo ser autóctono. Del puro ateniense al francés de raigambre. Trad. Sandra Garzonio. Buenos Aires: FCE, 2005. 15-54. Medio impreso. 
lo tanto, civilizarlo, negándole el rostro. Lo confina, entonces, a ser contenido del escudo: palabra de los hombres que olvidan el origen de su emisión.

El lugar que ha ocupado Atenea en esta, su propia experiencia de negación del Otro y, a la vez, fundamentación de la ontología griega, ha consistido en introducir un elemento que impide la derechura en la expresión del rostro, es decir, que impide la relación ética. La introducción de ese elemento (el escudo de Perseo) permite reducir la presentación del Otro a la dicotomía yo versus no-yo; en el caso griego, civilización versus barbarie. Esa interposición se coloca precisamente en la región en que el rostro de la Medusa y el rostro levinasiano coinciden: la altura que "[...] es altura en el rostro del Maestro [...] que viene de la otra orilla [y] enseña la trascendencia misma” (Lévinas, Totalidad 189). Perseo, a fin de cuentas, no experimenta la trascendencia, porque se le niega el maestro.

Si la coincidencia que aparece entre el rostro que problematiza Lévinas y la mirada de la Medusa consiste en el movimiento descrito por la enseñanza -desde su altura-, entonces, la experiencia que hereda en la tierra de Esquilo esta negación mítica de la autonomía del Otro es - por antonomasia- el teatro trágico. Las razones de esta contigüidad metonímica entre la Medusa y el escenario no se limitan de manera exclusiva al posible origen político del género, bajo la tiranía de Pisístrato -época en que la lírica también sufre modificaciones ideológicas sustantivas para la educación griega a posteriori-, es decir, a la imposición evidente de un rol pedagógico que nos permitiría pensar al espectador ateniense como un discípulo y a la tragedia como un maestro ${ }^{2}$, cuya altura se vería interrumpida por el escudo de la máscara. Esta prescripción, análoga a la evitación de la cara de Medusa en Perseo, trae consigo el mismo ocultamiento que propugna Atenea a través del asesinato de la gorgona: negar que alguna vez respondió al llamado de ese rostro, interrumpiendo el gozo de su morada.

De las tragedias que se conservan hasta hoy, la única que utiliza los materiales de la Atenas contemporánea para la construcción de su discurso corresponde a Los persas, de Esquilo. Representada en el 472 a.C., glorifica la victoria ateniense en Salamina frente al gran ejército de los persas. La acción transcurre en el palacio de la reina Atosa, y el público asiste a su mueca de dolor ante la inminente derrota que un emisario le comunica. La relación que la puesta en escena establece con el público es, en efecto, la que circunscribe Aristóteles en la Poética 1449b.25 como lo que "lleva a cabo" la imitación

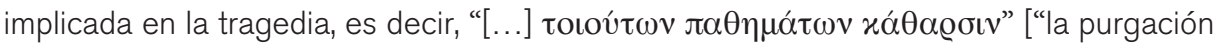

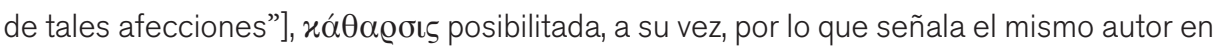
1453a.6-15 a propósito de la condición que deben tener los personajes representados, el carácter de la fábula y la peripecia (que, idealmente, debe ir de la dicha a la desdicha a causa de un gran yerro, “ó $\mu \alpha \varrho \tau i ́ \alpha v$ ”). El espectador entonces purga las afecciones al ver

2 Para comprender más en profundidad el carácter educativo de la tragedia ática, fundamentado en su origen religioso y popular, y de qué forma se modela como un género cuyo destinatario es, por excelencia, el $\delta \eta \mu o \varsigma$, véase Rodríguez Adrados, Francisco. "Esquilo y la ruptura del dilema trágico: teoría religiosa de la democracia". La Democracia ateniense. Madrid: Alianza. 1998. 128-158. Medio impreso. 
la caída de la gloriosa reina Atosa y, junto con ella, de todo el imperio de los persas, porque la puesta en escena provoca en él una emoción reflexiva que comprende la calamidad de ese Otro representado 3 .

No obstante, hay una consignación a propósito de otro tipo de $\pi \alpha ́ \theta \eta \mu \alpha$, uno que no logra ser subsumido, comprendido, apresado por la mano de Atenas y - por lo tanto- reducido a objeto regular de su gozo: el drama sobre la toma de Mileto. Los persas reaccionaron ante la sublevación jónica (494 a.C.) arrasando esta ciudad griega (Heródoto VI). Uno de los poetas de los que se tiene registro que escribieron dramas contemporáneos (tal como hizo Esquilo) es Frínico, quien, en efecto, compuso una obra al respecto y la presentó tal como Esquilo hizo con Los persas, solo que, esta vez, era el frente griego la víctima cuya fortuna caía de la dicha a la desdicha:

\section{[...] los atenienses manifestaron su gran pesar por la toma de Mileto de muchos modos y señaladamente al representar Frínico un drama que había compuesto sobre la toma de Mileto, no sólo prorrumpió en llanto todo el teatro, sino que le multaron en mil dracmas por haber renovado la memoria de sus males propios, $y$ prohibieron que nadie representase ese drama (Heródoto VI.21).}

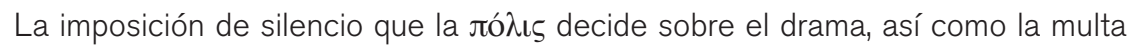
sobre el poeta, deja entrever una negación que suprime la presentación de ese rostro como lo absolutamente Otro. "La presentación del rostro -la expresión- no devela un mundo interior, previamente cerrado, que agrega así una nueva región para comprender y apresar. Me llama, al contrario, por encima del dato que la palabra pone ya en común entre nosotros" (Lévinas, Totalidad 225). Esa llamada desencadena otro jó $\theta \eta \mu \alpha$ que Aristóteles no contempla como emoción reflexiva en su definición de tragedia (porque el pueblo de Atenas no logra comprender la desgracia que ha puesto a los persas por sobre sus propias fuerzas) y es ignorada a través de la prohibición; gesto análogo al de Atenea guiando la mano de Perseo para ocultarle a la historia el mito de aquella muchachita que alguna vez osó compararse con ella y que, en efecto, consiguió el recibimiento de su rostro en la venganza de la diosa ${ }^{4}$.

3 La relación que establece el espectador (Mismo) con el personaje en la escena (Otro) queda inscrita en el lenguaje de la ontología y no en lenguaje de lo absolutamente Otro, precisamente porque el espectador aprehende, a través de la emoción reflexiva, la figura del Otro en lugar de permitir la irrupción de su rostro como mandato. Las razones de esa evitación tienen que ver con la máscara, punto que es necesario dilatar por el momento para dar cuenta de la única experiencia de que tenemos registro según la cual el teatro pudo, en efecto, mostrar alguna vez la cara del Otro.

4 Una de las lecturas más sugestivas a propósito de la prohibición de la representación de la Toma de Mileto corresponde a la que Nicole Loraux esboza en "De la amnistía y su contrario". La ciudad dividida. El olvido en la memoria de Atenas. Trad. Sara Vassallo. Madrid: Katz, 2008. 145-169. Medio impreso. Los procesos de amnistía en la Atenas democrática suponen el olvido de Estado con respecto a cualquier vestigio de división en la jó $\mathbf{\iota}$. Tanto las desgracias como las oposiciones deben ser tajantemente omitidas, querencia que encuentra sus máximos representantes en el castigo a Frínico por el recuerdo del fracaso griego en Mileto (y la prohibición de volver a representar el drama) y el retorno en el 403 a.C. de los demócratas una vez terminado el terrible régimen de los treinta tiranos de la mano de un “[...] decreto [que] proclama la prohibición: me mnesikakeîn, 'está prohibido recordar las desgracias' [...] [y un] juramento [que] compromete a los atenienses, ya sean demócratas, oligarcas o la gente 'tranquila' que se quedó en la ciudad durante la dictadura, pero los compromete uno por uno: ou mnesikakéso, 'yo no recordaré las desgracias' " (149). La autora (para sintetizar de manera injusta el argumento a estas alturas del libro) atribuye la prohibición con respecto al olvido al esfuerzo constante de la » 
Dos son los temores principales que Atenea contagia a la лó $\lambda$ ı n naciente del semen caído a tierra por causa de Hefestos, quien lo derramó impúdico sobre la pierna de la diosa: lo absolutamente Otro y el recuerdo de su rostro. En la decapitación de la Medusa reconocemos la negación del recibimiento del rostro (alguna vez la divinidad se tomó el trabajo de convertir al mortal en monstruo, saliendo de su gozo) y, entonces, permanecemos en el orden de la ontología que precisa el olvido de toda irrupción Otra en la historia de la ciudad. Con la prohibición explícita del rostro que la puesta en escena de la Toma de Mileto pone en evidencia, la comunidad ateniense acusa su conocimiento a propósito de las condiciones propias del arte teatral con respecto al traer a presencia en la escena: hic et nunc. Pero hay ciertos elementos que, pese a su raigambre religiosa, producirán en el teatro trágico un alejamiento de esta pretensión realista -más allá de la ordenanza por parte del Estado que prohíbe la agitación de cualquier otro jó $\theta \eta \mu \alpha$ que el razonadamente expuesto, a posteriori, por Aristóteles- y circunscribirán su manifestación al ámbito del idealismo: la máscara.

Con realismo invocamos aquello que el propio Lévinas intenta exponer en "Trascendencia y altura": "Para que la pretensión del realismo -el reconocimiento de un otro distinto de mí- sea posible, sería necesario que Yo-mismo no fuera originalmente lo que pertenezco hasta en mis exploraciones de lo oscuro o en lo desconocido -la tranquila y soberana identificación de sí consigo mismo, fuente de ideas apropiadas" (Lévinas, La realidad y su sombra 95). Vale decir, pretender realismo es admitir la presencia del Otro en tanto absolutamente Otro, obedecer a su mandato y no darle la muerte subsumiéndolo al idealismo que lo reconoce solo como negación de mí mismo. Podríamos decir que la capacidad del arte teatral de traer a presencia -característica reconocida también por Aristóteles cuando enuncia como $\mu$ ú tematizado en la tragedia (1449b.25) - puede acercarnos a ese realismo que permitiría al Otro manifestar la profética expresión de su rostro, y atender a que "[l]a relación con el otro en tanto que rostro sana de la alergia. Es deseo, enseñanza recibida y oposición pacífica del discurso" (Lévinas, Totalidad 210).

ciudad por autorrepresentarse discursivamente como indivisa y sin conflictos (como una especie de sujeto sin profundidad psicológica, porque no presentaría fracturas). Se pretende abordar un movimiento similar al de Loraux, pero en palabras de Lévinas y con algunas digresiones: este intento de la ciudad por mostrarse como única, en efecto, tiene como condición de posibilidad el ocultamiento de la fractura que resulta una evitación del recibimiento del Otro en derechura. La factura de una autorrepresentación impenetrable del Mismo (la ciudad como una, indivisa) no deja cabida sino a un Otro lógico (un no-yo). Lo que hace la jódıৎ al prohibir la puesta en obra de la Toma de Mileto es, a fin de cuentas, propiciar su olvido porque no puede comprender la expresión de ese rostro que, así como la constitución de un nuevo orden (como en el caso del retorno de los demócratas al poder en el 403 a.C.), implica indefectiblemente una violencia. Cfr. Derrida, Jacques. "Del derecho a la justicia”. Fuerza de ley. Madrid: Tecnos, 2002. 11-68. Medio impreso. Con respecto a esta violencia que parecería introducir la apelación del rostro (que puede deducirse de la interrupción del goce del Mismo), es sugestivo contrastar lo que el mismo Lévinas señala contrariamente en "Libertad y mandato": "La oposición de la cara, que no es oposición de una fuerza, no es una hostilidad. Es una oposición pacífica, pero en la que la paz no es en absoluto una tregua, una violencia contenida. La violencia consiste, al contrario, en ignorar esta oposición, en ignorar el rostro del ser, en evitar la mirada y en entrever el sesgo por donde el no inscrito en la cara, pero inscrito sobre la cara por el hecho mismo de que es cara, se vuelve una fuerza hostil o sometida" (77). Esta violencia que niega la autonomía del Otro es distinta con respecto a aquella que separa al Mismo de su gozo. 
Esta posición privilegiada que ocuparía el teatro ático trágico como manifestación escénica situada en derechura al espectador -geometría que nos recuerda la altura de la que procede la enseñanza del rostro- ve truncadas sus pretensiones realistas con la presencia de la máscara 5 . Su presencia en la escena tiene como justificación el origen religioso del género, como nos lo recuerda Werner Jaeger ${ }^{6}$. Empero, la mostración a través de una máscara (que para los griegos tenía el propósito de convertir al actor en el personaje elevado que interpretaba a los ojos del público) obtiene como efecto posible la representación de un Otro que, por lo tanto, no alcanza a serlo absolutamente. Es por causa de esa máscara que fija la movilidad de la expresión en una mueca precisa, legible, que se signa y consigna al actor y a su personaje como un no-espectador, es decir, únicamente como el que actúa, como un Otro que no alcanza a ser autónomo. El Otro cae entonces en la región de lo representable, de lo comprensible y "[l]a inteligibilidad, el hecho mismo de la representación, es la posibilidad para el Otro de ser determinado por el Mismo, sin determinar el Mismo, sin introducir alteridad en él, ejercicio libre del Mismo" (Lévinas, Totalidad 143).

El vocablo griego con que Aristóteles consigna la palabra máscara corresponde a

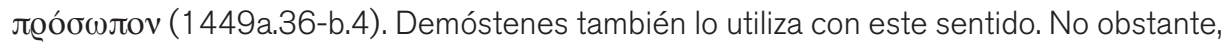

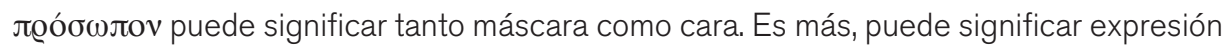
del rostro y, a causa de su constitución etimológica (delante de la faz), el "estar delante de" puede ser trascendente (la expresión) o inmanente (la máscara). Es tal la ambigüedad de su interpretación, que Heródoto lo emplea -al describir la figura del ibis de Arabia- como pico de pájaro (II.76), precisamente por ser rostro, expresión y máscara del ave.

Sin embargo, en la mayoría de las fuentes preplatónicas, la traducción más adecuada pareciera ser rostro, faz y, en algunos casos, expresión (vale decir, se abre una ventana a la trascendencia). En el caso de Homero -por ejemplo-, en llíada 7.12 (describiendo la

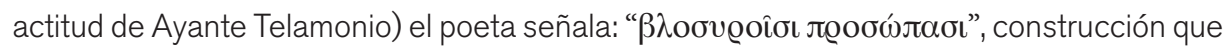
Luis Segalá y Estalella traduce felizmente por "con torva faz".

Los casos que nos son más relevantes, empero, pertenecen al género de la tragedia.

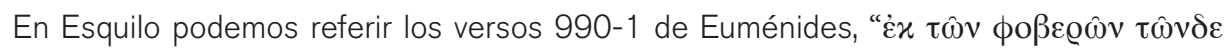

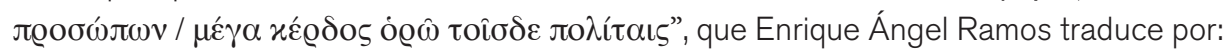
"De estos rostros terroríficos veo surgir gran provecho para estos ciudadanos", en alusión a las Erinias que, luego de que Atenea cumplimente su voluntad vengadora, sean subsumidas

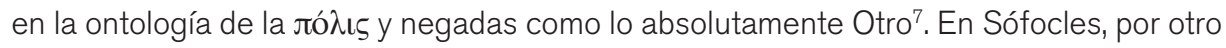

5 “La posición de cara, la oposición por excelencia, sólo es posible como juicio moral. Este movimiento parte del Otro" (Lévinas, Totalidad 209). Esta posición es la que se niega en Atenas: a la derechura del actor frente al espectador se la desvía con una máscara comprensible. Se desvía la mirada temerosa, como Perseo frente a la gorgona.

6 "Otro elemento era la magnificencia del espectáculo [...]. Basta recordar la máscara trágica, tan frecuente en el arte griego, para darse cuenta de esta diferencia. En ella se hace visible la diferencia esencial de la tragedia griega y cualquier otro arte dramático posterior. Su distancia de la realidad ordinaria era tan grande que la fina sensibilidad de los griegos halló en la trasposición y parodia de sus palabras a las situaciones de la vida cotidiana una fuente inagotable de efectos cómicos. Todo en el drama se realiza en una esfera de la más alta elevación y ante espectadores henchidos de piedad religiosa" (Jaeger 232-3).

7 Supondremos a este respecto que Atenea se venga siempre del Otro que la interrumpe decapitando la cabeza de Medusa y, por lo tanto, ocultando su rostro. 
lado, Antígona profiere en los versos 311-4 de Edipo en Colono lo siguiente: " $v u v a i x$ '

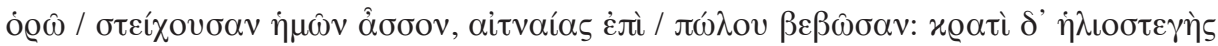

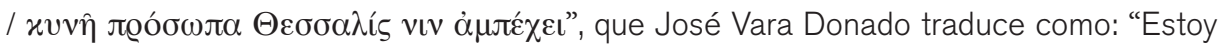
viendo a una mujer que cada vez se viene acercando más a nosotros cabalgando sobre una potra del Etna, y sobre su cabeza un gorro tesalio que la protege del sol le cubre la cara". Es Ismene que viene al encuentro de su hermana y de su padre, toda familia que le resta, tal como Odiseo vuelve luego de diez años de errar por el mediterráneo -dibujando el nostálgico movimiento de la filosofía de Occidente-8; pero no es un regreso a la Tebas maldita por los dioses, es un retorno al oîxos desplazado (una reinserción al Mismo, de todas formas). Final, aunque no menos significativamente, el caso de Eurípides también

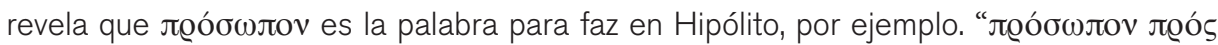

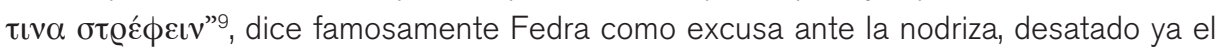
drama de su amor por el hijastro.

\section{III}

Los citados ejemplos de Esquilo y Eurípides resultan valiosos para comprender de qué

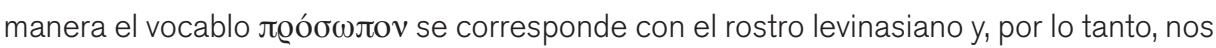
ayuda a entender cómo el temor de los atenienses a su manifestación desnuda justifica la osificación de la máscara en el ejercicio teatral.

Lévinas señala a propósito del rostro que “[...] se niega a la posesión, a mis poderes. En su epifanía, en la expresión, lo sensible aún expresable se transforma en resistencia total a la aprehensión. Esta mutación sólo es posible por la apertura de una dimensión nueva" (Lévinas, Totalidad 211). La cualidad distintiva del rostro con respecto al Otro entendido como un Otro lógico guarda relación directa con su carácter epifánico; la propuesta radical tras la manifestación del rostro corresponde a la reubicación de la luz, que debemos atribuir a otra fuente que la mayéutica -que, bajo la figura de la partera, nos ayuda a parir luz propia-: si el intelecto atiende a la apelación del Otro absolutamente Otro es, precisamente, a causa de este Otro. La autonomía que se manifiesta en el llamado imposibilita al Mismo: no es capaz de apropiarse de quien aparece, de frágil rostro, esperando una respuesta.

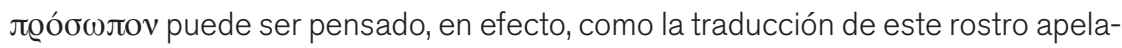
tivo, porque pareciera querer mostrar más que la materialidad de la cara, es decir, aludiría

8 De Ismene podríamos decir que "[v]iene de la casa y a ella retorna, movimiento de la Odisea en la que la aventura corrida en el mundo sólo es el accidente de un retorno” (Lévinas, Totalidad 194).

9 Transcribimos acá la intervención completa de Fedra. Hemos marcado en negrita las palabras que los traductores de Gredos escogieron para solucionar el extracto: "Has hablado bien. Después de haber recurrido a todo, sólo hallo un remedio en mi desgracia para conceder a mis hijos una vida honorable y obtener yo misma un beneficio en mis actuales circunstancias. Nunca deshonraré, segura estoy de ello, a mi patria cretense, ni me presentaré ante los ojos de Teseo bajo el peso de mi vergonzosa acción, sólo para salvar mi vida” (715-720). David Kovacs traduce el mismo destacado por: "[...] [N]or shall I go to face Theseus [...]". 
a la expresión: en la conversación entre la Nodriza y el Corifeo de Hipólito, a propósito del estado anímico de Fedra, el vocablo -traducido por cara- demuestra que, en ella, hubo un Otro para el Mismo Teseo (hubo, porque ahora, en boca del Corifeo, ese rostro se tematiza y, por lo tanto, deja de serlo): "Nodriza: Morir, sin duda. No come para acabar con su vida. / Corifeo: Es extraño lo que dices, si su esposo no hace nada. / Nodriza: Ella oculta su mal y niega que está enferma. / Corifeo: ¿Y él no acierta a descubrirlo, al mirarla a la cara? / Nodriza: Se encuentra de viaje fuera de esta tierra" (276-81, el énfasis es nuestro). Una lástima la ausencia de Teseo. Quizá, estando en casa, hubiera respondido de alguna forma a la fragilidad de ese rostro y evitado su propia tragedia. Por su parte, el público de Atenas tampoco logra ver el rostro de Fedra: se oculta, de manera tendenciosa, detrás de la máscara que ahoga el gesto. ¿De qué sería capaz el jefe del oîxos al mirar en la faz de esa mujer que suplica? Probablemente, de no matar.

Al mismo tiempo, “[m]anifestarse como rostro es imponerse más allá de la forma, manifestada como puramente fenomenal, presentarse de una manera irreductible a la manifestación, como la rectitud del cara a cara, sin la mediación de la imagen en su desnudez, es decir, en su miseria y su hambre" (Lévinas, Totalidad 213). El impedimento en Teseo para recibir en derechura al rostro que es su mujer sugiere un paso superficial de la mirada por un fenómeno solo inmanente. Nodriza, en cambio, en la irrestricta defensa que hace de su ama a lo largo de la tragedia, nos permite entrever que ella sí ha recibido al Otro ${ }^{10}$. La dimensión sensible del rostro (y por lo tanto la no sensible), no obstante, es negada en la escena. El espectador no accede en derechura a la mirada de Fedra: hay una máscara que se interpone entre el público y el Otro autónomo, que late oculto, ignorado, decapitado como la Medusa.

El movimiento que la máscara viene a intervenir es aquel que describe el lenguaje que es propio del rostro; se coloca cual escudo que protege al público de la altura de ese maestro: “Al cuestionamiento del yo, coextensivo de la manifestación del Otro en el rostro, lo llamamos lenguaje. La altura desde donde viene el lenguaje la designamos por la palabra enseñanza. La mayéutica socrática tenía razón frente a una pedagogía que introdujese las ideas en un espíritu al violar o al seducir (que viene a ser lo mismo) este espíritu" (Lévinas, Totalidad 189). La enseñanza del rostro se distancia de la mayéutica socrática precisamente en la reubicación de la luz: la altura del Otro levinasiano llama y ordena al Mismo a reconocer, en un profundo intento de realismo, su autonomía, vale decir, a no matarlo en la comprensión ontológica. Esta ordenanza implicaría el reconocimiento de ese Otro lenguaje que no sale a la luz gracias a la partera, sino que se constituye como enseñanza en la altura de su procedencia y su afán disruptivo. "La enseñanza es un discurso en el que el maestro puede aportar al alumno lo que el alumno aún no sabe. No opera como mayéutica, pero continúa la introducción en mí de la idea de lo Infinito. La idea de lo Infinito implica un alma capaz de contener más de lo que puede sacar de sî” (Lévinas, Totalidad 197).

10 Interesante hacer notar aquí que el personaje subordinado, Otro por lo tanto, sea el único capaz de dar recibimiento al rostro. 
Que el lenguaje del rostro sea distinto de la mayéutica, implica que no puede ser

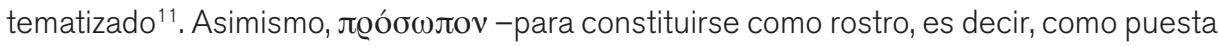
en escena de la Toma de Mileto, como presencia de Teseo recibiendo en derechura el rostro de Fedra, como actor sin máscara interpretando a las Erinias frente al público de la Atenas del siglo V a.C.- tampoco puede ser tematizado. En tal caso, deja de ser rostro; vale decir, resulta subsumido por el lenguaje de la ontología. La máscara evita la comunicación de este lenguaje Otro, que se aproxima en el movimiento de la enseñanza, en la erupción de lo absolutamente Otro. Por lo tanto, solo nos resta la palabra; y que actor

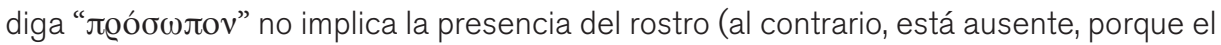
rostro aparece, no se dice).

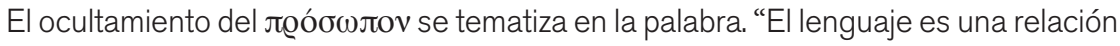
entre términos separados. Al uno, el otro puede ciertamente presentarse como un tema, pero su presencia no se reabsorbe en su jerarquía de tema. La palabra que se refiere a otro como tema parece contener al otro. Pero ya se dice a otro que, en tanto que interlocutor, ha dejado el tema que lo englobaba y surge inevitablemente detrás de lo dicho" (Lévinas, Totalidad 208). Esta aparición es negada a través de la máscara: el personaje no puede aparecer como un absolutamente Otro, no cumplimenta el Deseo metafísico en el que observa, no logra constituirse en un quien -solo se mantiene como un que--12; el Otro es reabsorbido por el Mismo, no se mantiene independiente tras lo dicho, como emisor, como interlocutor de sí como tema, sino que se lo oculta tras el reflejo de un escudo.

Si pensamos en la relación de doble ocultamiento que el rostro de las Erinias mantiene para con Atenea al interior del drama, por un lado, y para con el público, por otro, notaremos de qué forma el movimiento de la enseñanza y su lenguaje es cercenado. Los diálogos que

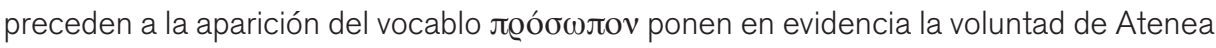
por asimilar a las Erinias a la unidad de la ciudad, es decir, por devolverlas al Mismo, pese al enojo furibundo de aquellas por la absolución de Orestes en el juicio acerca de la muerte de su madre. Las diosas antiguas han quedado desprovistas de toda función que antaño les era propia a causa del racionalismo ateniense. Ya no persiguen a los delincuentes de su propia sangre, esa labor le corresponde ahora, y gracias a Atenea, a los hombres. La hija de Zeus ha guiado los movimientos de Orestes para negar a las Erinias, ahora Euménides, tal y como guió la mano de Perseo para cortar la cabeza de la Medusa. Lo que intermedia esta vez, en lugar del escudo, es la aparición de un tribunal que suplanta el ejercicio de la violencia que, anteriormente, era privativo de las hermanas vengadoras.

Pudiera parecer tendencioso de nuestra parte comparar el asesinato de la gorgona con la transformación de las Erinias, pero es efectivo que ambas subsunciones se explican por la alergia de Atenea frente al Otro. Si revisamos el texto esquileo notaremos que las diosas vengadoras no tienen alternativa ninguna frente a la violencia que la hija de Zeus

11 “Lo infinito no podría ser tematizado (...)" (Lévinas, Totalidad 224).

12 "A la pregunta ¿́quién? responde la presencia no cualificable de un ente que se presenta sin referirse a nada que, sin embargo, se distingue de todo otro ente. La pregunta ¿quién? refiere a un rostro" (Lévinas, Totalidad 195). 
imprime en la amenaza a las hermanas. Palas saca rápidamente las garras. Deja en claro que pese a la sabiduría de esas viejas donosianas, nada pueden hacer frente a su vigor juvenil y que la Persuasión es, divina, la violencia que les deja como alternativa o aceptar la propuesta de convertirse al Mismo o morir (que es equivalente). El ofrecimiento de la morada en el templo de Erecteo, ese primer hombre que nació del semen de Hefestos y del acto negador que la virginal mano de la diosa comete, sacudiéndolo de su pierna -negación de hijo que albergará a la negación del Otro- llega tarde, pues ya ha proferido Atenea la amenaza capital: "Soy la única de los dioses que conoce las llaves de la morada en la que está sellado el rayo” (828-30). Toda conversación posterior tendrá la forma protocolar de un acto persuasivo que, a fin de cuentas, demora lo que las Erinias tardan en rendirse frente al temor de la violencia impenetrada.

"De estos rostros terroríficos veo surgir gran provecho para estos ciudadanos" (9901), señala Atenea. El rostro de las Erinias ha desaparecido en la representación de las Euménides. El miedo a la desnudez de ese rostro, tan advertido a su jó $ı$ ı por la diosa, ha conseguido la comprensión del Otro (y por lo tanto su reducción) ${ }^{13}$. Ese miedo desaparece también con respecto a los espectadores. De estos rostros terroríficos, ellos solo ven las máscaras. En la representación escénica, en la fijeza del gesto, hacia el Otro oculto tras la materialidad de esa máscara -hacia el rostro compungido por esa ajenidad dibujada- se dirige una violencia negadora, que proviene de los ojos atenienses que miran sin ver; se niega al Otro como lo absolutamente Otro:

La violencia es una manera de actuar sobre todo ser y toda libertad abordándola de soslayo. La violencia es una manera de apoderarse del ser sorprendiéndolo, de apropiarlo a partir de su ausencia, a partir de lo que no es realmente él. La relación con las cosas, el dominio de las cosas, esa manera de estar por encima de ellas, consiste precisamente en no abordarlas nunca en su individualidad (Lévinas, La realidad y su sombra 77).

Esta forma de relación violenta con respecto a la alteridad parece la única posible dentro de la comunidad griega, que se pretende indivisa. Es necesario negar la autonomía con respecto a todo Otro, así como frente a cualquier fisura del Mismo, lo que equivale a decir que, en términos de discurso, la ciudad no admite sino su propia constitución como sujeto (pero un sujeto sin fracturas), porque la alteridad al interior de su comunidad es, en

13 Cuando hablamos de miedo a la desnudez del rostro por parte de los habitantes de Atenas pensamos en las siguientes palabras de Lévinas: "La absoluta desnudez del rostro, este rostro absolutamente sin defensa, sin cobijo, sin vestido, sin máscara, es, sin embargo, lo que se opone a mi poder sobre él, a mi violencia, lo que se opone a ella de modo absoluto, con una oposición que es oposición en sî" (La realidad y su sombra 80). El deseo de la тó $\lambda ı \varsigma$ ateniense por autorrepresentarse como única, es decir, la querencia irrestricta de inadmitir la irrupción de un Otro (y, aún más, la erupción de un Otro desde su propia comunidad), y la concesión de su autonomía, es la causa que fundamenta la negación del Otro en la continuidad del goce y, por lo tanto, la perpetración de violencia en ese Otro que es Medusa, que es Erinia y que es actor. En este sentido, es importante subrayar que el rostro levinasiano no se reduce a la cara; en lo que se ha intentado demostrar hasta acá, el ocultamiento físico de la cara por parte de la máscara se alinea con otra serie de elementos que pretenden ser negados, que constituyen la expresión de un otro al que no se da hospedaje. 


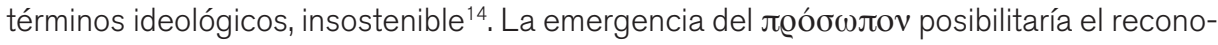
cimiento de un absolutamente Otro dentro de la ciudad Misma, incluso el de un individuo griego. Mas esa división, ese Otro, solo tendrá lugar en la praxis, no en los registros ${ }^{15}$. Baste con citar al Otro más redimido de todos, a las Euménides subsumidas por el Mismo:

Suplico que la discordia civil, nunca en esta ciudad brame, que nunca, bebiendo el polvo sangre de ciudadanos, por ira acoja con venganza la avidez de una muerte por muerte [esta aseveración soslaya por completo que las tres hermanas han renunciado a la autonomía de su alteridad, manifestada en la venganza de sangre; prueba de negación absoluta], ruina de la ciudad. Que gozo por gozo se devuelvan con pensamiento concorde y que odien con un solo corazón, pues éste es un remedio entre los mortales de muchos males (Esquilo 980-89).

Inmediatamente después de este parlamento, Atenea se atreve a enunciar la pa-

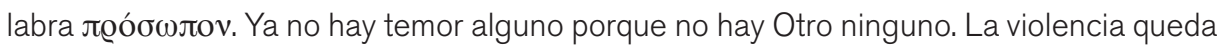
permitida de manera manifiesta. Una violencia de Uno en contra de Otro, que aniquila el discurso del rostro y osifica el gozo del Mismo. Representadas las Erinias como Euménides y cosida la cabeza de Medusa a la égida, resta preguntarse cómo ese ocultamiento alevoso se perpetúa en la tradición grecolatina.

\section{Referencias}

Apolodoro. Biblioteca mitológica. Barcelona: Akal, 1987. Medio impreso.

Aristóteles. Poética. Trad. Valentín García Yebra. Madrid: Gredos, 1992. Medio impreso.

Constant, Benjamin. "Sobre la libertad de los antiguos comparada con la de los modernos".

14 La concepción de una libertad negativa en el mundo griego es prácticamente imposible. Eso justifica, en parte, las dificultades que encuentra Hannah Arendt para hablar de esfera privaday esfera pública a propósito de los griegos en La condición humana. Tal parece que cualquier tipo de interés "privado" pierde sentido luego de las reformas democráticas sucesivas que, tras Clístenes, disuelven de iure el influjo de la fratría en el ejercicio de los cargos políticos de Atenas. Constant dirá al respecto que "[...] entre los antiguos, el individuo habitualmente casi soberano en los asuntos públicos, era esclavo en todas sus relaciones privadas. Como ciudadano, decidía sobre la paz y la guerra, como particular, estaba limitado, observado, reprimido en todos sus movimientos; como parte del cuerpo colectivo, interrogaba, destituía, condenaba, despojaba, exiliaba, atacaba a muerte a sus magistrados o a sus superiores; como sometido al cuerpo colectivo, podía ser, a su vez, privado de su estado, sus dignidades, desterrado a muerte, por la voluntad discrecional del conjunto del que formaba parte" (Constant 53).

15 Este ocultamiento tras la máscara se circunscribe en una serie de actos similares efectuados discursivamente por la comunidad ateniense de los siglos V-IV a.C., de los cuales el principal pareciera ser la negación de la otóoıı. Loraux afirma que "[...] más allá de todas las denegaciones y todos los olvidos, lo que es preciso olvidar o denegar es el hecho de que la stásis sea connatural a lo político griego. Olvidar el pasado sería entonces, en el contexto de cada amnistía cívica, repetir un olvido muy antiguo: el olvido de esos tiempos inmemoriales -si es que existieron- en que el conflicto regulaba la vida en común" (Loraux 64-5). Tal parece que pese al carácter ético del rostro de Lévinas, en el caso griego es imperativo ocultarlo y esa prescripción nos hace sospechar que el reconocimiento del Otro en tanto que absolutamente Otro es una cuestión fundamental y política en Atenas. Pudiéramos esbozar la hipótesis de que la permisión de la derechura en el recibimiento de ese rostro provocaría algo más que el despertar del individuo en una comunidad que lucha por autorrepresentarse como sujeto sin fracturas, en otras palabras, cuya única forma de libertad debiera ser positiva. Tal parece que esa unidad que niega la multiplicidad al interior de su vientre, niega, también, la autonomía de cualquier Otro (bárbaro) que se presente en el horizonte de su historia. Por eso es tan necesario olvidar la Toma de Mileto, porque constituye el registro de un discurso que admite la inaprehensibilidad de ese Otro que se atrevió a quemar los altares del Mismo. 
Estudios Públicos. 1995: 51-68. Medio impreso.

Detienne, Marcel. Cómo ser autóctono. Del puro ateniense al francés de raigambre. Trad.

Sandra Garzonio. Buenos Aires: FCE, 2005. Medio impreso.

Eurípides. "Hipólito". Tragedias I. Trad. A. Medina et al. Barcelona: Gredos, 2006. Impreso.

Esquilo. “Euménides”. Tragedias. Trad. Enrique Ángel Ramos Jurado. Madrid: Alianza, 2001.

265-303. Medio impreso.

Heródoto. "Libro sexto. Erato". Los nueve libros de la historia. Trad. María Rosa Lida de

Malkiel. Buenos Aires: Clásicos Jackson, 1956. 329-374. Medio impreso.

Homero. Ilíada. Traducido por Luis Segalá y Estalella. Medio impreso.

Jaeger, Werner. "El drama de Esquilo”. Paideia. México: FCE, 1980. 223-47. Impreso.

Lévinas, Emmanuel. La realidad y su sombra. Libertad y mandato, Trascendencia y altura.

Madrid: Trotta, 2001. Medio impreso.

---. Totalidad e Infinito. Salamaca: Sígueme, 2006. Medio impreso.

Loraux Nicole. La ciudad dividida. El olvido en la memoria de Atenas. Trad. Sara Vassallo.

Madrid: Katz. 2008. Medio impreso.

Rodríguez Adrados, Francisco. "Esquilo y la ruptura del dilema trágico: teoría religiosa de la democracia”. La Democracia ateniense. Madrid: Alianza. 1998. 128-158. Medio impreso.

Sófocles. “Edipo en Colono”. Tragedias completas. Trad. José Vara Donado. Madrid: Cátedra, 2007. 391-456. Medio impreso.

Recibido: 27 marzo 2013

Aceptado: 24 mayo 2013 